\title{
Mesoscale vortex over Lake Baikal: A case-study
}

\author{
A. A. Shestakova ${ }^{1}$ and Repina, I. A. ${ }^{1}$ \\ Received 16 March 2021; accepted 1 April 2021; published 11 September 2021.
}

This paper presents the results of a case-study of lake-effect circulation over Lake Baikal in December 2012, when the lake surface was still almost free from ice. The most spectacular manifestation of lake effect was a mesoscale vortex over the northern part of the lake. The analysis of this phenomenon is based on satellite observations, in-situ measurements, as well as on mesoscale numerical modeling with the WRF-ARW model. The model reproduced well the time and location of the vortex observed, correctly featuring cloud structures and time course of meteorological parameters near the surface, though it was less accurate reproducing precipitation due to some space shift between observed and simulated landfall location.

Sensitivity experiments revealed the role of the warm lake surface and orography in the vortex generation and intensification. Unlike vortices over the American Great Lakes, where orography is small and the main reasons of vortex formation are breeze circulation and diabatic heat fluxes from the surface, considered Baikal vortex was formed primarily due to orography-induced convergence. Orography generated conducive conditions for local winds and breeze circulation and to a large extent formed unstable temperature stratification due to partial blocking of the incoming flow. KEYWORDS: Mesoscale vortex; lake-effect precipitation; WRF-ARW; vorticity.

Citation: Shestakova, A. A. and Repina I. A. (2021), Mesoscale vortex over Lake Baikal: A case-study, Russ. J. Earth. Sci., 21, ES5001, doi:10.2205/2021ES000763.

\section{Introduction}

Many different forms of organized convective clouds can be seen from space over the ice-free lakes during the cold season - separate convective clouds, roll convection, shoreline bands and finally mesoscale vortices (or mesocyclones) [Laird and Kristovich, 2004. Such phenomena are described in detail over the American Great Lakes [Forbes and Merritt, 1984, Laird, 1999; Laird and Kristovich, 2004. Pease et al., 1988. In Russia, such phenomena are expected over large lakes (Onega and Ladoga Lakes, Lake Baikal), which, due to their size and depth, are not covered with ice in the beginning of winter. Wintertime lake-effect precip-

\footnotetext{
${ }^{1}$ A. M. Obukhov Institute of Atmospheric Physics RAS, Moscow, Russia
}

Copyright 2021 by the Geophysical Center RAS. http://rjes.wdcb.ru/doi/2021ES000763-res.html itation are common on the southern coast of the Caspian Sea [Ghafarian et al., 2017; Khoshakhlagh et al., 2016, Shestakova and Toropov, 2021.

From a scientific and practical point of view, the most interesting circulations are mesoscale vortices, which may be associated with heavy precipitation [Pease et al., 1988]. The mechanisms of formation of such lake vortices are usually similar to those for polar lows and tropical cyclones. Generation and intensification of any vortex can be considered from the point of view of the vorticity equation:

$$
\begin{aligned}
& \frac{\partial(\zeta+f)}{\partial t}=-\bar{v} \nabla(\zeta+f)- \\
& w \frac{\partial(\zeta+f)}{\partial z}-\nabla \bar{v}(\zeta+f)- \\
& \left(\frac{\partial w}{\partial x} \frac{\partial v}{\partial z}-\frac{\partial w}{\partial y} \frac{\partial u}{\partial z}\right)+\frac{1}{\rho^{2}} \nabla p \nabla \rho
\end{aligned}
$$

where $\zeta$ - vertical component of relative vorticity, $f$ - Coriolis parameter, $\bar{v}-$ horizontal wind vec- 
tor, $w$ - vertical component of wind speed, $p$ - air pressure, $\rho$ - air density. First two terms in the right side of the equation are horizontal and vertical advection of absolute vorticity, respectively, the third term is vorticity divergence ("stretching" term), the fourth term is a tilting term (transformation from horizontal to vertical vorticity) and the last term is solenoidal (baroclinic) term.

While the main sources of vorticity for synopticscale cyclones are vorticity stretching and baroclinicity, the role of baroclinic term is significantly reduced (especially for thermally symmetric vortices) and impact of other terms is increased for the mesoscale vortices. Although for many polar vortices baroclinic instability plays an essential role in the appearance of initial perturbations, baroclinic instability alone is insufficient to explain the polar low development [Rasmussen and Turner, 2003. There are two common thermal instability mechanisms of mesoscale vortex intensification - CISK (Conditional Instability of Second Kind), first proposed for the tropical cyclone [Charney and Eliassen, 1964, and WISHE (Wind-Induced Surface Heat Exchange) [Emanuel and Rotunno, 1989. According to the former mechanism, the main source of cyclonic vorticity is latent heating due to condensation in clouds. The contribution of latent heating can be significant not only for tropical, but also for polar mesocyclones, as shown by numerous numerical experiments with and without taking into account the heat of condensation [e.g., Albright et al., 1995, Claud et al., 2004; Verezemskaya and Stepanenko, 2016. The latter mechanism (WISHE) assumes that vortex intensification occurs mainly under the influence of turbulent heat fluxes from the surface due to wind speed enhancement in the vortex. However, both theories are applicable under the assumption that initially some cyclonic circulation already exists, that is, they do not explain the occurrence of an initial disturbance. The most general overview of polar mesoscale cyclones and their mechanisms can be found in [Rasmussen and Turner, 2003. Terpstra and Watanabe, 2020 .

Lake vortices are limited by lake sizes and thus are smaller than polar lows and typically from 10 to $100 \mathrm{~km}$ in diameter [Laird, 1999]. Small vortices arise due to horizontal wind shear (barotropic, shear-line vortices), while large vortices are already more like polar lows, since the release of diabatic heat plays an important role in their formation. It is generally accepted that the "stretching" and "tilting" of vorticity, as well as diabatic heating (primarily, surface turbulent heat fluxes) are key factors in lake vortices formation, while advection of vorticity does not play a great role [Forbes and Merritt, 1984 Laird, 1999]. Configuration (curvature) of lake coastline is also important for lake vortices formation, similar to the role of sea ice shape in polar low formation [Albright et al., 1995, Heinemann, 1997]. Vortices over the Great Lakes are usually formed under weak wind and weak vertical wind shear conditions, against the background of pressure ridges [Forbes and Merritt, 1984]. Strong wind disturbs the local breeze (the source of flow convergence) and unfavorable for vortex generation. With a strong wind blowing parallel to the main axis of the lake, a band of clouds is formed instead of mesocyclones, which is perpendicular to the wind and parallel to the coast and often leads to strong precipitation, both over the lake and on land [Laird and Kristovich, 2004]. Moreover, with a weak wind, a particle moving from the land over the lake experiences the effect of heating from the surface for a longer time and thus the low pressure over the lake is maintained longer. Laird et al., 2003 noted that a good criterion for separating different forms of lake convection is the ratio of wind speed to the path traveled by the flow over the lake (fetch). A distinctive feature of lake vortices is that they are observed only at low values of this criterion, less than $0.05 \mathrm{~m} \mathrm{~s}^{-1} \mathrm{~km}^{-1}$ [Laird and Kristovich, 2004.

The occurrence of deep convection over the lake in winter leads to intense snowfalls on the coast [e.g. Alcott and Steenburgh, 2013. Niziol, 1987, Nicholls and Toumi, 2014, which means that these phenomena are significant for regional weather forecasting. For example, Davsha meteorological station on the northeastern coast of Lake Baikal (Figure 1) has a local maximum of precipitation in November (in addition to the main maximum of precipitation at the end of summer), which is absent at other stations. The amount of precipitation on the west coast of Baikal is generally much less than on the east [Mizandrontseva, 1970] due to the foehn effect during the westerly winds. At the same time, the effect of increased precipitation on the east coast, especially in late autumn and early winter, may also be related to the lake effect. Local 


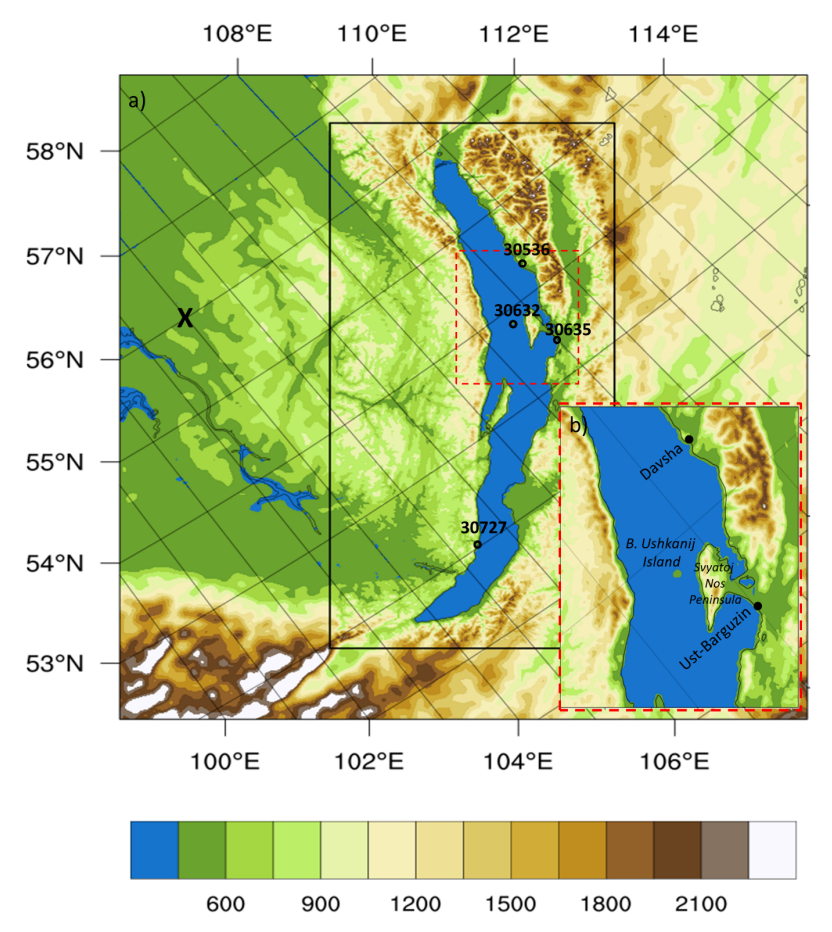

Figure 1. a) Model domains (nested domain is bounded with black rectangle). Color shows orography height (in meters above sea level (a.s.l.)); weather stations are marked with empty circles and WMO indices. Black cross shows the point where incoming flow was analysed. b) Zoomed area of interest (bounded with red rectangle in Figure 1a) with names of localities.

weather services can predict the possibility of lakeeffect convection under certain synoptic conditions, but it is impossible to predict the exact location of mesoscale vortex formation and associated precipitation without high-resolution numerical model. In this regard, one of the goals of this work was to assess the quality of lake-effect circulations simulation over Lake Baikal using a mesoscale model. We used the WRF-ARW model, which has proven itself in predicting similar events in other regions [e.g., Shestakova and Toropov, 2021.

Besides, the mechanisms of the mesocyclone generation over Lake Baikal was analyzed on the example of one case and the similarity of this vortex with polar lows and lake vortices over the American Great Lakes were highlighted. In contrast to the Great Lakes, the analysis of the circulation over Lake Baikal is complicated by the orography, generating many local winds, which become more frequent in late autumn and early winter [Naydenov, 2015: Savinova, 1977]. In some regions, orogra- phy plays an important role in the formation of mesocyclones, not only facilitating the convergence of flows, but also modifying thermodynamic fields [e.g., Gallée, 1995, Klein and Heinemann, 2002. Kristjánsson et al., 2011; Watanabe et al., 2018. Therefore, to differentiate the influence of orography and the lake effect on the formation of the vortex, additional sensitivity experiments were carried out.

\section{Data and Methods}

Images of the MODIS spectral radiometer from the Terra satellite were used as the main source of data on cloudiness for identifying mesoscale circulations over Lake Baikal, as well as on the lake surface temperature (LST). For the Baikal region, these satellite images are available in the interval 11:00-13:00 (hereafter, local time is used, which is $\mathrm{UTC}+8 \mathrm{~h}$ ). Images are available at https://world view.earthdata.nasa.gov/and https://ladsweb.mod aps.eosdis.nasa.gov/.

The WRF-ARW model version 4.2 was used as a main tool for studying mesoscale circulations over Lake Baikal. Simulations were carried out for the period from 12 December to 16, 2012, when mesoscale circulations and, in particular, a mesocyclone were detected from satellite images. The computational domains (Figure 1) had a resolution of $5 \mathrm{~km}$ in the parent domain and $1 \mathrm{~km}$ in the nested domain (bounded with black rectangle in Figure 1). Both domains had 70 vertical levels with the lower level set at $10 \mathrm{~m}$ above ground level (a.g.l.). The following set of parametrizations was used: WSM6 [Lim and Hong, 2010] for cloud microphysics; RRTMG [Iacono et al., 2008] for radiative fluxes; MYNN [Nakanishi and Niino, 2006 for surface and boundary layers; NoahLSM [Tewari et al., 2004 for land surface. Spectral nudging was applied for wavelengths greater than $1000 \mathrm{~km}$ and only for the parent domain above the atmospheric boundary layer.

Three numerical experiments were run. In the control (CTRL) experiment, the CFSv2 reanalysis (Climate Forecast System version 2, [Saha et al., 2011) with a time step of $6 \mathrm{~h}$ was used as the initial and boundary conditions. Second experiment (named WRF-ERA5) was run with ERA5 reanalysis (Copernicus Climate Change Service (C3S), 
a)

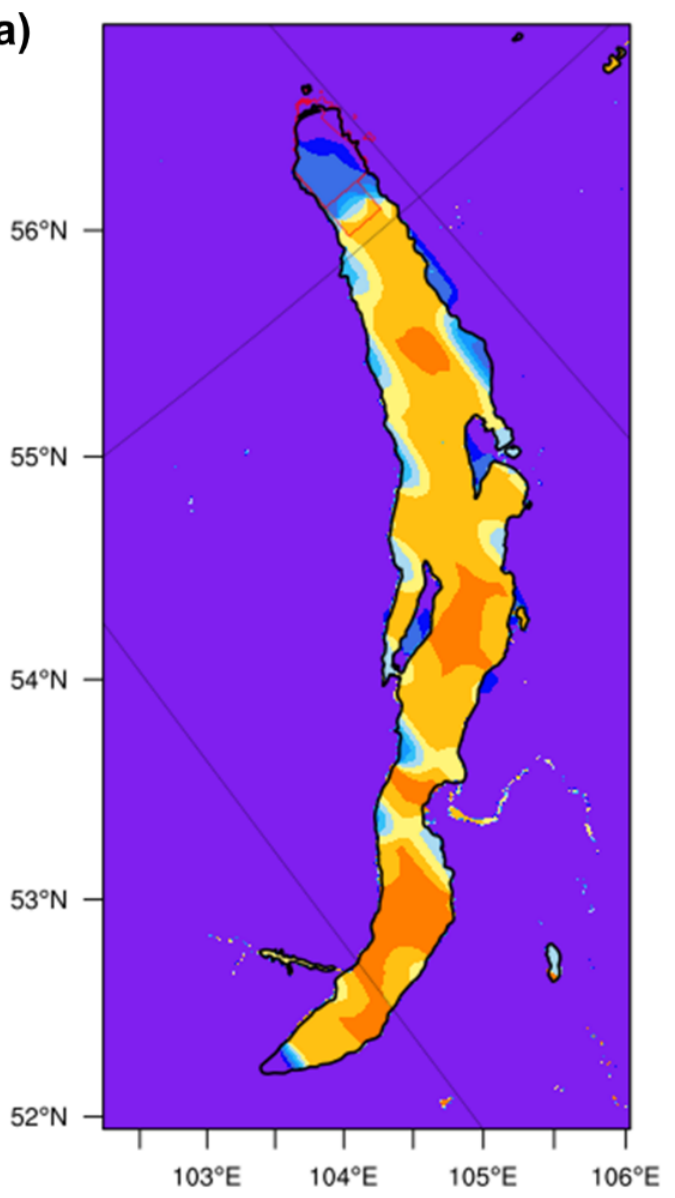

b)

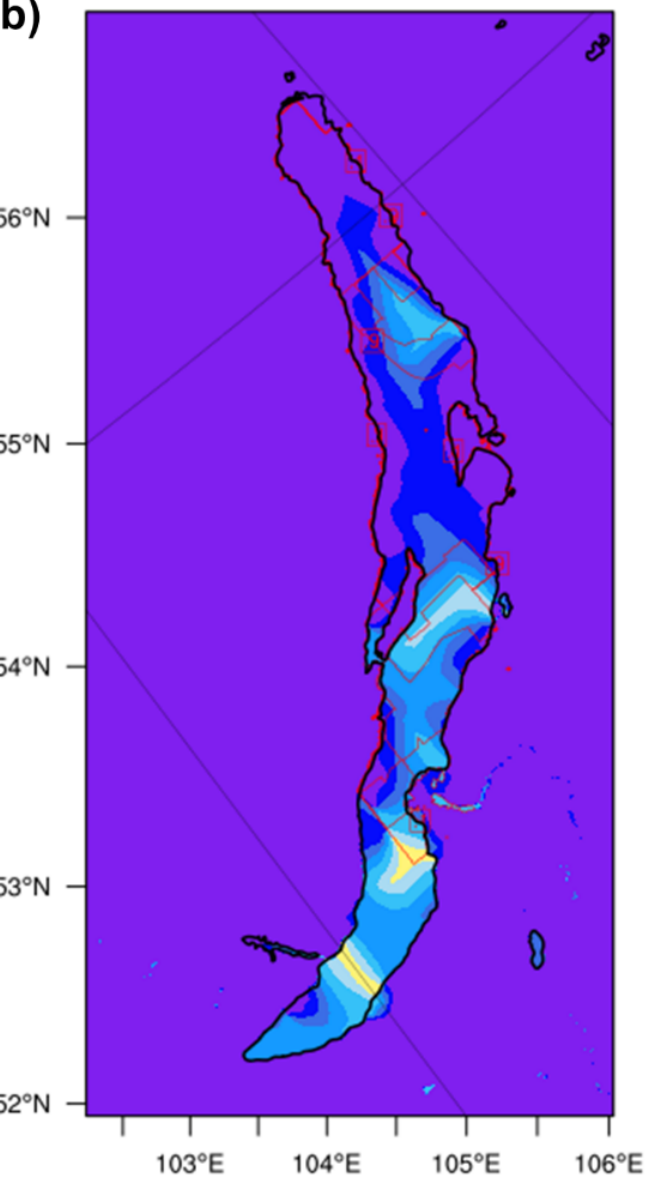

Surface temperature, ${ }^{\circ} \mathrm{C}$

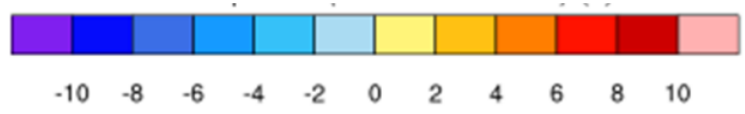

Figure 2. Surface temperature (color) and sea ice fraction (red contours, from 0.1 to 0.9 every 0.4) at 08:00 12 December 2012 from CFSv2 (a) and ERA5(b) interpolated on WRF-ARW grid.

2017, ERA5: Fifth generation of ECMWF atmospheric reanalyses of the global climate. Copernicus Climate Change Service Climate Data Store (CDS), https://cds.climate.copernicus.eu/cdsapp\# !/home) with a time step of $3 \mathrm{~h}$. The ice concentration and, accordingly, the lake surface temperature differed much in these two reanalyses in the considered case. While most of the lake was free of ice in CFSv2 (Figure 2a), which is close to satellite observations, most of the northern half and part of the southern half of the lake was covered with ice in ERA5 (Figure 2b). As a result, LST in ERA5 was lower than that in CFSv2 by more than 10 degrees. Thus, these two experiments not only aimed to reveal the best source of initial data, but to some extent to demonstrate the role of a warm lake (lake effect) on the formation of the detected mesoscale circulations.

The third experiment (FLAT) differed from the CTRL only in that the height of the orography in both domains was set equal to the height of the water level of Lake Baikal, i.e. $449 \mathrm{~m}$. Comparison of CTRL and FLAT experiments aimed to reveal the role of orography in the formation of the detected circulations.

To verify simulation results, the following weather stations were used: Davsha (WMO index 30536), Ust-Barguzin (30635) and Bolshoe 
Goloustnoe (30727), situated on the coast of the lake, and Bolshoij Ushkanij Island (30632) Figure 1). Measurements of the main meteorological parameters were carried out 8 times a day, and two times a day (at 00:00 and at 12:00 UTC) precipitation were measured. In addition, the data of radiosounding at the Ust-Barguzin station, carried out 2 times a day (at 00:00 and at 12:00 UTC), were used. The data are freely available at http://www.meteo.ru.

\section{Satellite Observations and Synoptic Situation on 12-16 December 2012}

Figure 3 shows satellite images on 13-16 December 2012, picked at about 12:00 local time. Various forms of organized convection are seen on these images for all days except for 14 December, when the cloudiness of the lower layer was overlapped by the frontal cloudiness of the middle and upper layers. Cloud rolls in the south of the lake stretching along the wind (westerly) were especially clearly seen on 16 December, when there was the strongest background flow. In the northern and central parts of the lake, and also in the southern part on 13 December, there was a band of clouds elongated along the main axis of the lake, which snuggled closer to the eastern shore. The presence of such a band indicates the convergence of winds from the western and eastern coasts. Finally, a very interesting feature is the spiraliform cloud feature near Svyatoj Nos Peninsula, observed on 15 December Figure 3), strongly resembling a mesocyclone, with a diameter of about $60 \mathrm{~km}$ and a cloud-free "eye" in the center. Top height of convective lake-induced clouds generally did not exceed $1 \mathrm{~km}$ a.g.l. (and therefore such clouds refer to shallow convection), though individual clouds reached a height of $2.5 \mathrm{~km}$ a.g.l. These accumulations of thicker clouds were noted in the northern half of the lake to the north of Svyatoj Nos Peninsula on 13 December, directly in the peninsula area on 15-16 December and to southeast of the peninsula on 16 December.

In general, considered episode was observed against the background of Siberian anticyclone, the center of which at the beginning of the episode was over the Ural Mountains and during the episode shifted to the east. Simultaneously, cyclones on the Mongolian branch of the polar front moved along the southern periphery of the anticyclone, over Mongolia and southern Siberia. Cyclones passed through Baikal region on 12 and 14 December. Between these two cyclones, a high pressure ridge passed over the lake on 13 December (Figure 4a). Cyclone passage on 14 December was accompanied by weak temperature ridge at $850-\mathrm{hPa}$ level Figure $4 \mathrm{~b}$ ). In the middle troposphere, the westerlies prevailed until 14 December. At the same time, the wind speed was relatively low and did not exceed $5-10 \mathrm{~m} \mathrm{~s}^{-1}$ in the lower troposphere. Starting from 15 December, steady northwestern flows prevailed at all altitudes (Figure 4k, Figure 4d), and a northern and northeastern flow was noted in the middle troposphere on 16 December. The wind speed increased significantly, and the $850-\mathrm{hPa}$ temperature decreased sharply on 16 December.

\section{Simulation Results}

\subsection{Vortex Dynamics According to Observations and Control Experiment}

The mesoscale vortex detected in the satellite image on 15 December was reproduced by the model in a control experiment. Its position is close to the observed one. Satellite-derived and simulated cloud top heights inside the vortex also coincided (Figure 5a, Figure 5b). The vortex cloud system at the moment of the image consisted of two spiral bands of clouds, and the vortex's "eye" was seen in the center. In simulation, the vortex "eye" formed two hours later than the observed one, at 14:00.

In the image on 16 December, the vortex itself was no longer seen (Figure 3), but one could see clusters of thick clouds, most likely belonging to the vortex, in the satellite image and simulation results. Obviously, the vortex came ashore near Svyatoj Nos Peninsula, which led to heavy snowfall at Ust-Barguzin station (Figure 6). The model greatly underestimated the amount of precipitation at this station (Figure 6), which can be explained by the more northerly position of the vortex landfall in the model compared to observations.

It is impossible to find out the time of vortex initiation from satellite observations with daily temporal resolution. The vortex was not found in the images on 13 and 14 December. However, the simulation results indicated that vortex appeared over 

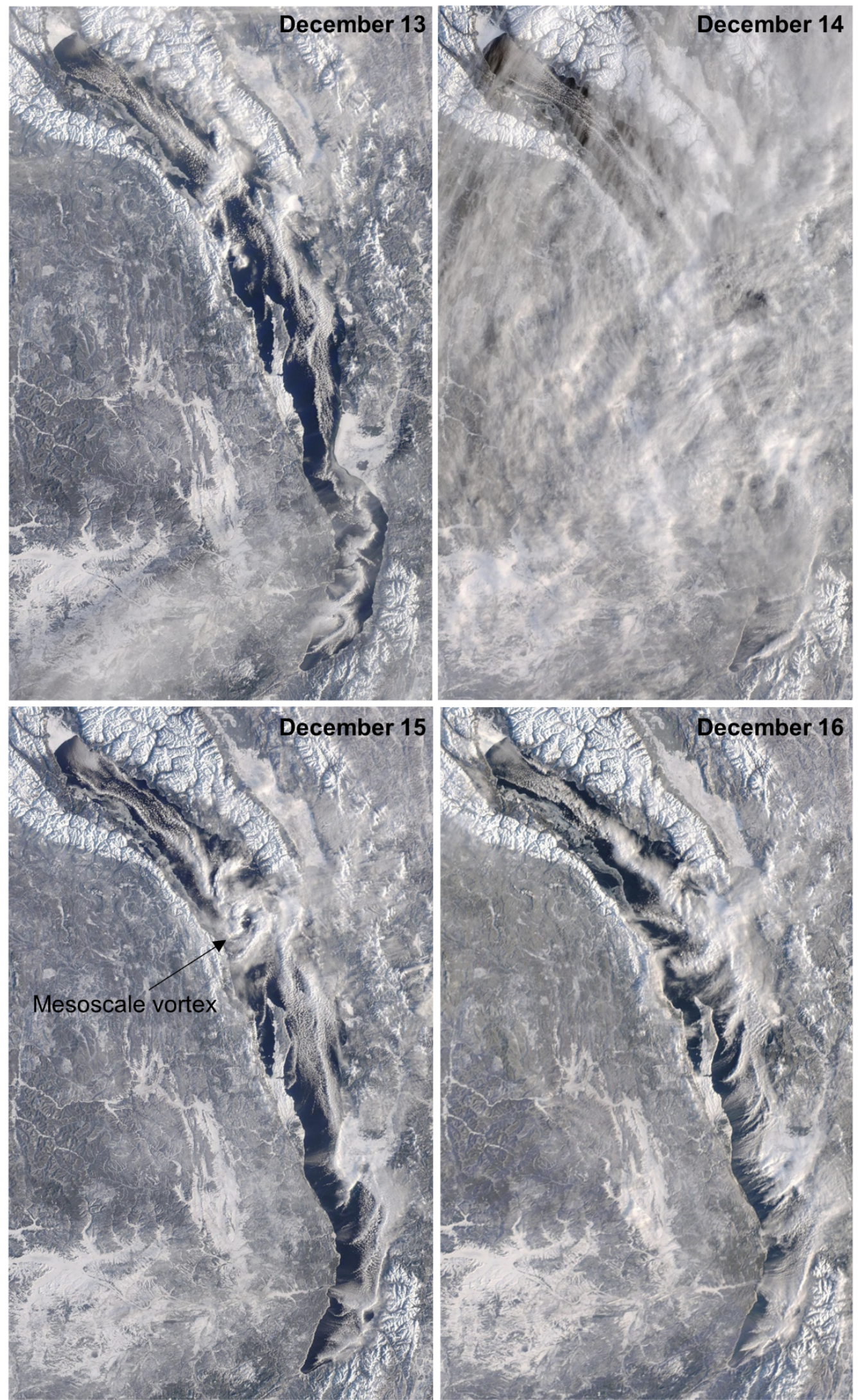

Figure 3. Evolution of cloudiness over Lake Baikal during the period 13-16 December 2012 as seen from Terra/MODIS satellite system. 

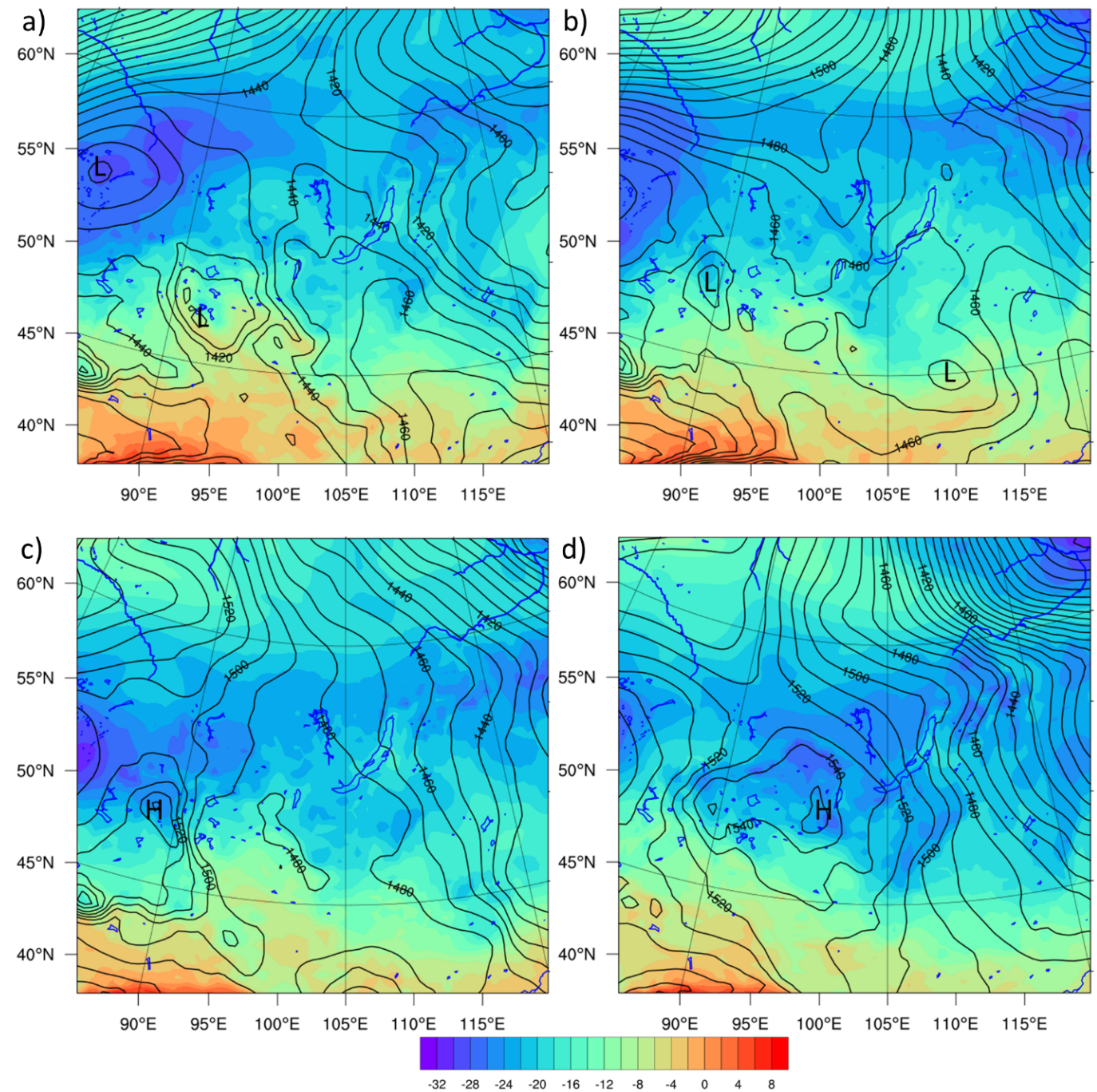

Figure 4. $850-\mathrm{hPa}$ level height (contours, every $10 \mathrm{~m}$ ) and temperature (color, in ${ }^{\circ} \mathrm{C}$ ) at 08:00 on 13 December (a), 14 December (b), 15 December (c) and 16 December (d) from CFSv2.

the lake in the area of Davsha station almost immediately after the model start, in the evening of 12 December. It was mesoscale vortex that could explain the moderate to heavy snowfall and cumulonimbus clouds, observed and simulated at this station on 13 December (Figure 6), since there were no synoptic fronts at this time (Figure 4a). According to simulations, the intensity of precipitation in this mesocyclone reached $20 \mathrm{~mm}$ per $3 \mathrm{~h}$ over the lake, although the amount of precipitation at the station was underestimated in comparison with observations (probably due to the shift of the model vortex relative to the observed one). Satellite observations on 13 December showed a cluster of dense clouds with the top height at $2.5 \mathrm{~km}$ a.g.l. near Davsha station (Figure 3). During the day, the vortex was rather stationary (see trajectory on Figure 5b); in the evening on 13 December, it began to move south, towards Svyatoj Nos Peninsula, and at 08:00 on 14 December it was no longer traced in simulations. During this period from the evening of 13 December to midday on 14 December - cumulonimbus clouds and heavy snowfall were observed at the station Bolshoij Ushkanij, which was on the path of this vortex. On the night of 15 December, the vortex reappeared to the west of the peninsula (Figure $5 \mathrm{~b}$, filled circles with trajectory line) and stayed in one place until the end of the day; later it went on land and collapsed. This vortex led to heavy snowfall at Bolshoij Ushkanij station at night and in the morning of 15 December. Most likely, these two vortices (on 12-13 De- 

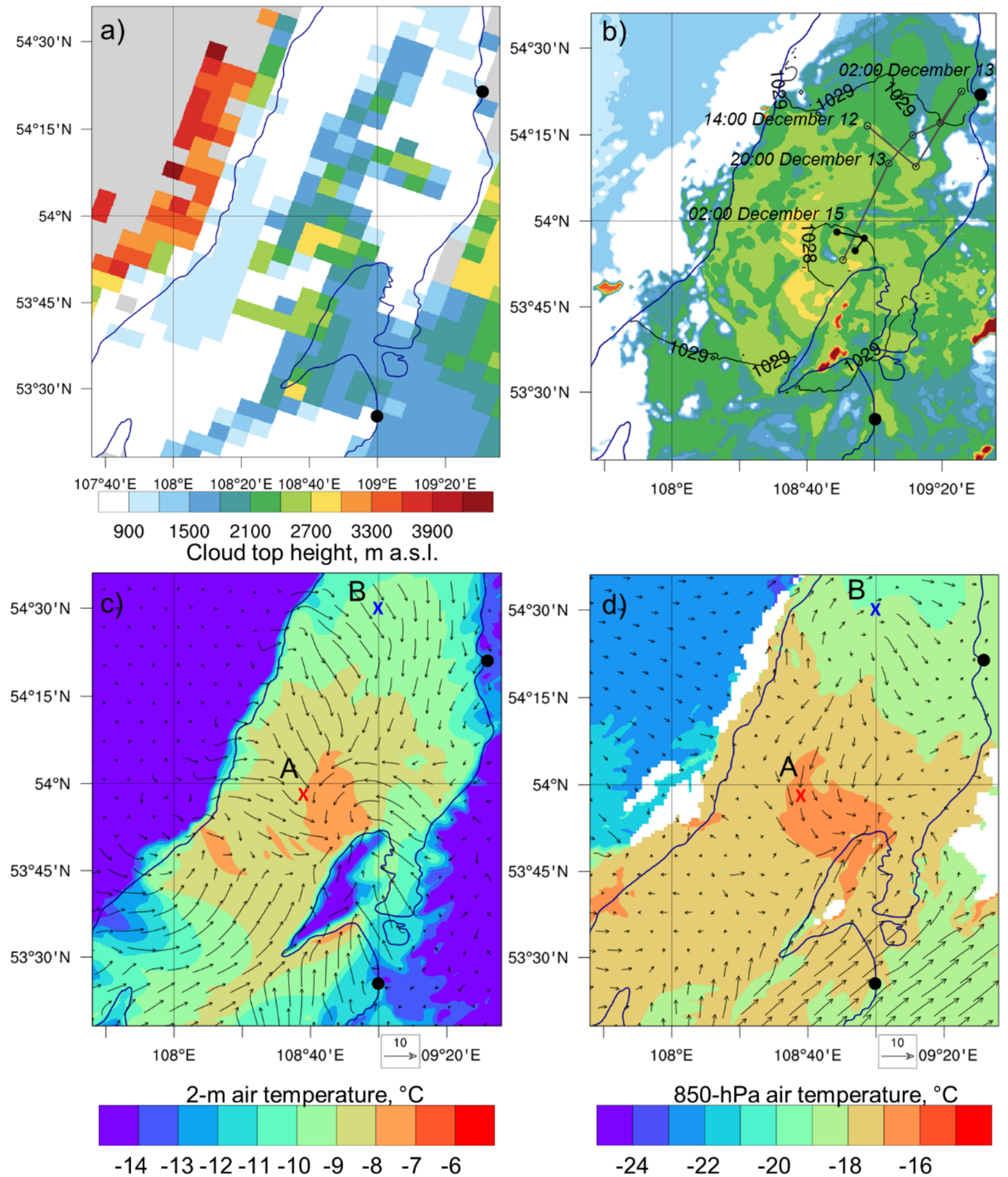

850-hPa air temperature, ${ }^{\circ} \mathrm{C}$

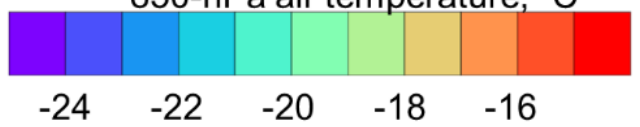

Figure 5. a)-b) Cloud-top height in the mesoscale vortex on 15 December according to MODIS 5-km data (a) (at 12:20) and simulation (b) (at 12:00). Figure 5b also shows sea-level pressure (over the lake, in contours, every $1 \mathrm{hPa}$ ) and vortex trajectory with time resolution $6 \mathrm{~h}$ from 06:00 12 December to 02:00 14 December (with gray line and empty circles) and from 02:00 to 14:00 15 December (with black line and filled circles). c)-d) Air temperature and wind vectors c) near the surface (at $2 \mathrm{~m}$ and $10 \mathrm{~m}$ a.g.l., correspondingly) and d) at 850-hPa level at 12:00. Stations 30536 and 30635 are shown with big black points. 
cember and on 15 December) must be referred to one episode, because the temporary disappearance of the vortex was associated with the strong largescale forcing on 14 December, which ended by the evening of 14 December when the vortex revived again.

\subsection{Experiments With ERA5 and CFSv2 as Initial and Boundary Conditions}

In this Section, simulation results of CTRL and WRF-ERA5 experiments, using CFSv2 and ERA5 reanalyses, respectively, as initial and boundary conditions for the simulation, are discussed. Figure 7 shows comparison of cloudiness and wind field in different experiments. In contrast to the control experiment (top panel), model did not reproduce mesocyclones on 12-13 December and 15 December in their full development in the WRFERA5 experiment (central panel in Figure 7). Only weak, small-scale near-surface vortices scarcely manifested in cloud fields (with cloud top height of $1-1.5 \mathrm{~km}$ a.g.l.) could be distinguished in the WRF-ERA5 experiment (as in the case of 15 December). The lifetime of these vortices was short (less than one day), with one closed isobar (if drawing isobars every $1 \mathrm{hPa}$ ), and with no closed isohypse at $850-\mathrm{hPa}$ level. At the same time, the differences between CTRL and WRF-ERA5 experiments were rather small in the southern half of the lake, since it was mostly ice-free in the ERA5 reanalysis.

The CTRL experiment also performed better when compared with surface data (Figure 6). This is especially evident at station 30632 , which is located near the center of the lake (on the island). At this station, the air temperature in the WRFERA 5 experiment was underestimated by $5-10$ degrees. There was also a noticeable improvement in wind direction simulation when using the initial conditions CFSv2. In addition, there were almost no precipitation in the WRF-ERA5 experiment (due to the small thickness and water content of the clouds), while $28 \mathrm{~mm}$ at station 30536 and 36 $\mathrm{mm}$ at station 30635 had fallen during the period 12-16 December. However, the CTRL experiment also underestimated the amount of precipitation at stations 30536 and 30635; at the same time, precipitation was greatly overestimated at station 30632 on 15 December, where the vortex reappeared.
Figure 8 shows a comparison of two experiments with radiosonde observations at Ust-Barguzin station. During the episode, the air in the lower and middle troposphere was close to saturation. Until 15 December, a surface inversion was noted at this station, and only on 16 December, the stratification at the station became unstable. Obviously, the temperature stratification in the boundary layer, as well as the dew point temperature (both in the lower and in the upper troposphere) and the wind vector were reproduced much better in the CTRL experiment than in the WRF-ERA5 experiment.

Thus, the advantage of using CFSv2 data in our case is not in doubt. The atmosphere was too "dry", and temperature stratification was more stable than observed due to improper ice and LST in ERA5, which led to the absence of deep convection systems in general and a mesocyclone in particular in the WRF-ERA5 experiment.

\subsection{FLAT Experiment and Discussion of Vortex Mechanisms}

Simulations revealed only small values of convective available potential energy (CAPE) (not shown) in the CTRL experiment during the whole episode. At the same time, atmospheric fronts were far from the lake when vortices appeared. Thus, the thick cloud clusters detected on satellite images were not caused by a forced large-scale air ascent on atmospheric fronts or free convection (as usually is the case in summer in mid-latitudes). There must be some other driving force to initiate convection, and this force was probably the vertical motions in the vortex center due to mass convergence. In turn, the initial mass convergence was provided not by deep convection over the lake (for example, due to the release of heat of condensation), since deep convection was secondary to the vortex, but by some other factor, presumably orography. To confirm this hypothesis, a FLAT experiment without orography was carried out, in which the mesocyclone was absent (Figure 7, bottom panel). Some cloudiness and even light precipitation appeared in the FLAT experiment, however, for the most part, the vertical scale of cloudiness was limited by the boundary layer. In this experiment, flow convergence over the lake was small.

The influence of orography was manifested primarily in flow convergence over the lake. The fea- 
a)
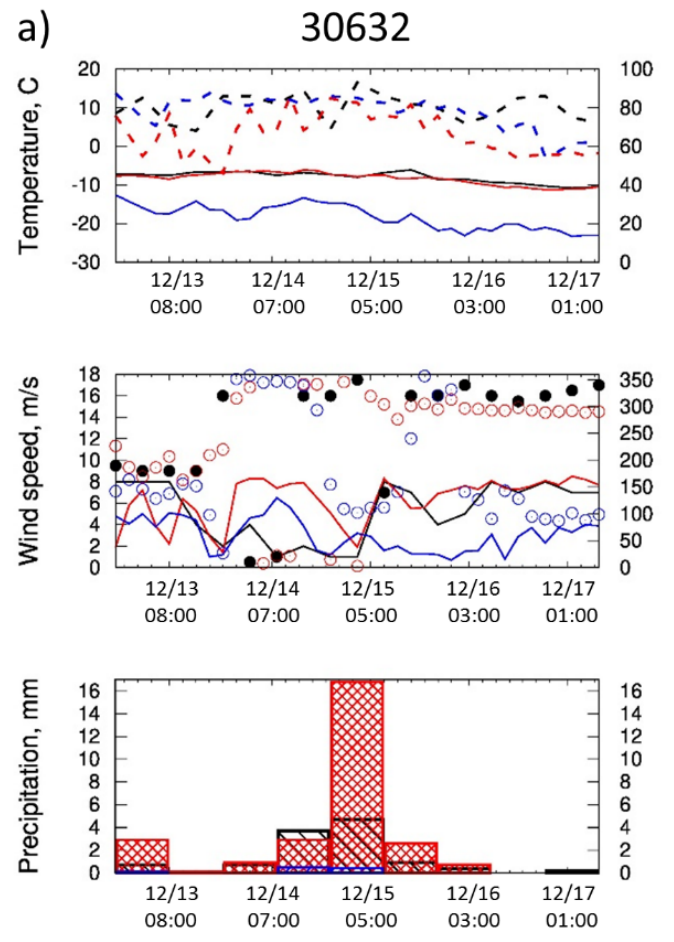

c)
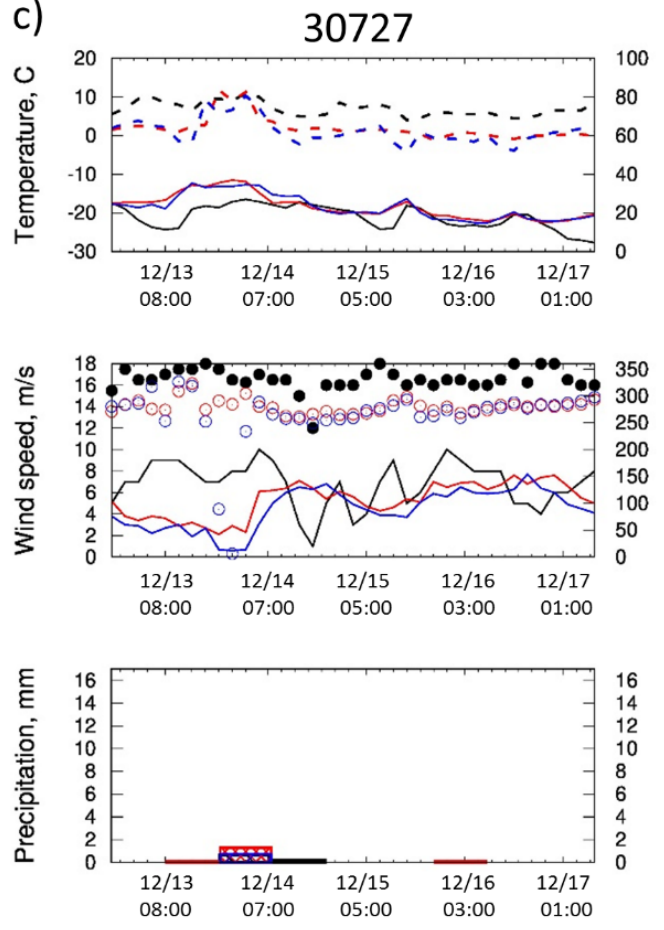

b)

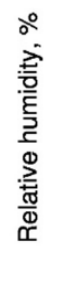

30536
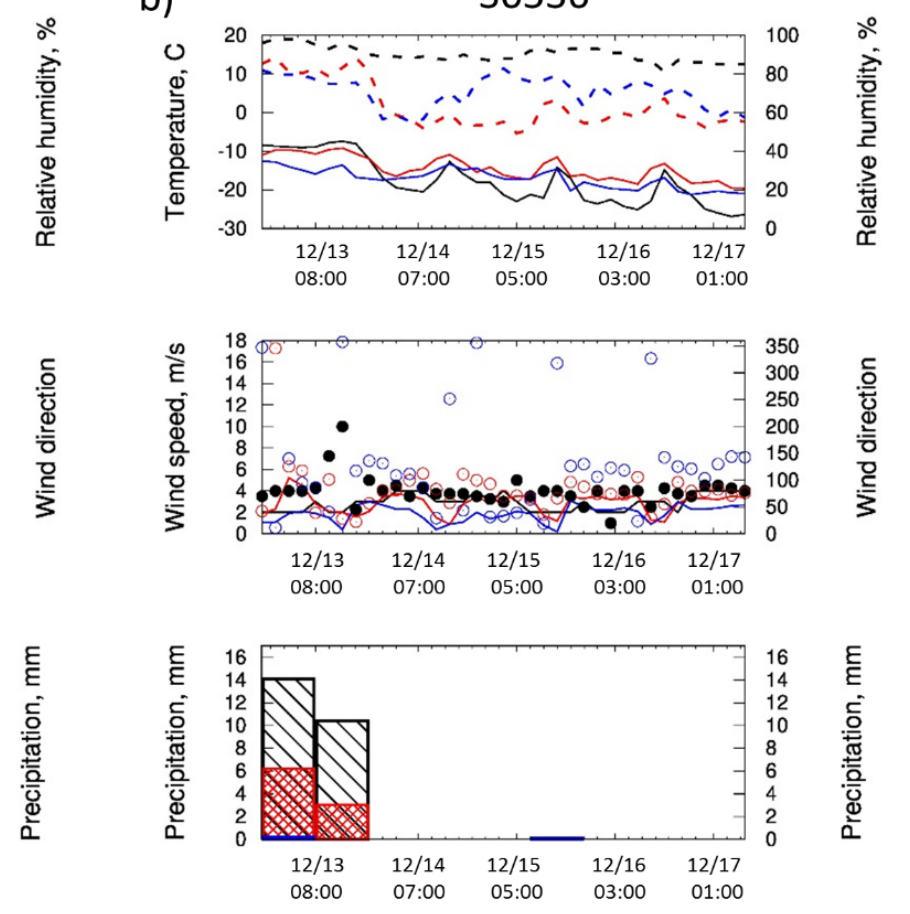

d)
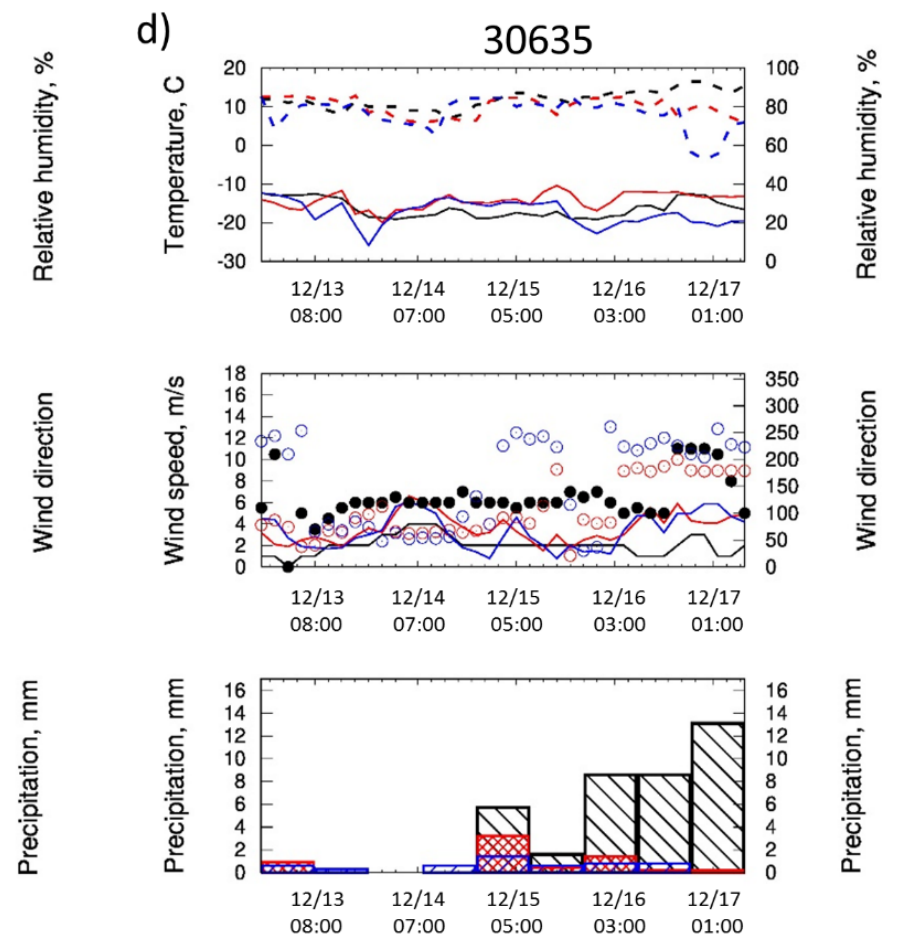

Figure 6. Time series of $2-\mathrm{m}$ air temperature (solid lines), relative humidity (dashed lines), 10-m wind speed (solid line), wind direction (circles) and 12-h sum of precipitation according to observations (black) and WRF-ERA5 (blue) and CTRL (red) experiments at stations 30632 (a), 30536 (b), 30727 (c) and 30635 (d). 

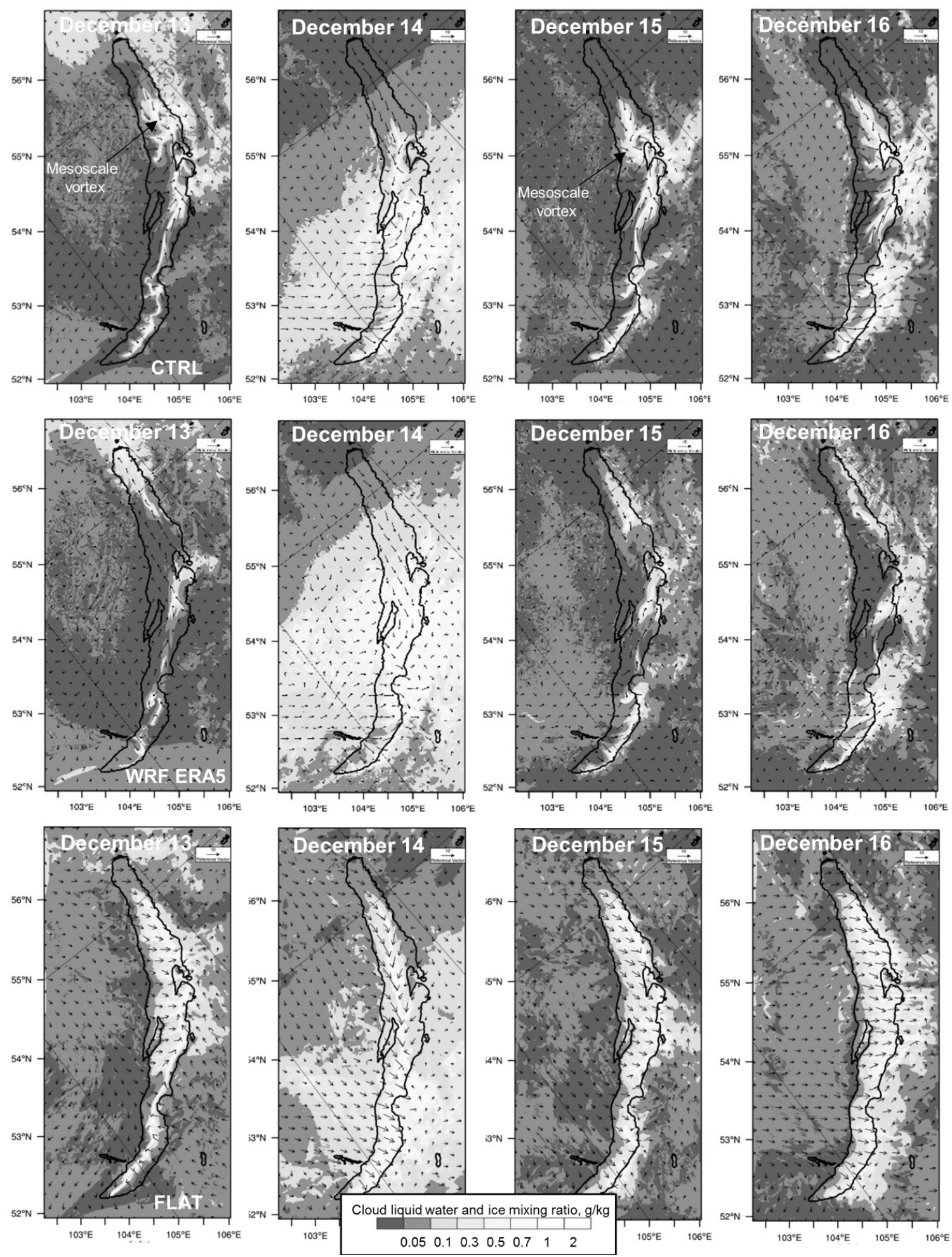

Figure 7. Cloud liquid water and ice mixing ratio (g/kg, in grayscale) and $10-\mathrm{m}$ wind vectors from WRF-ARW simulations in CTRL (top), WRF-ERA5 (center) and FLAT (bottom) experiments at 12:00 on 13-16 December. 

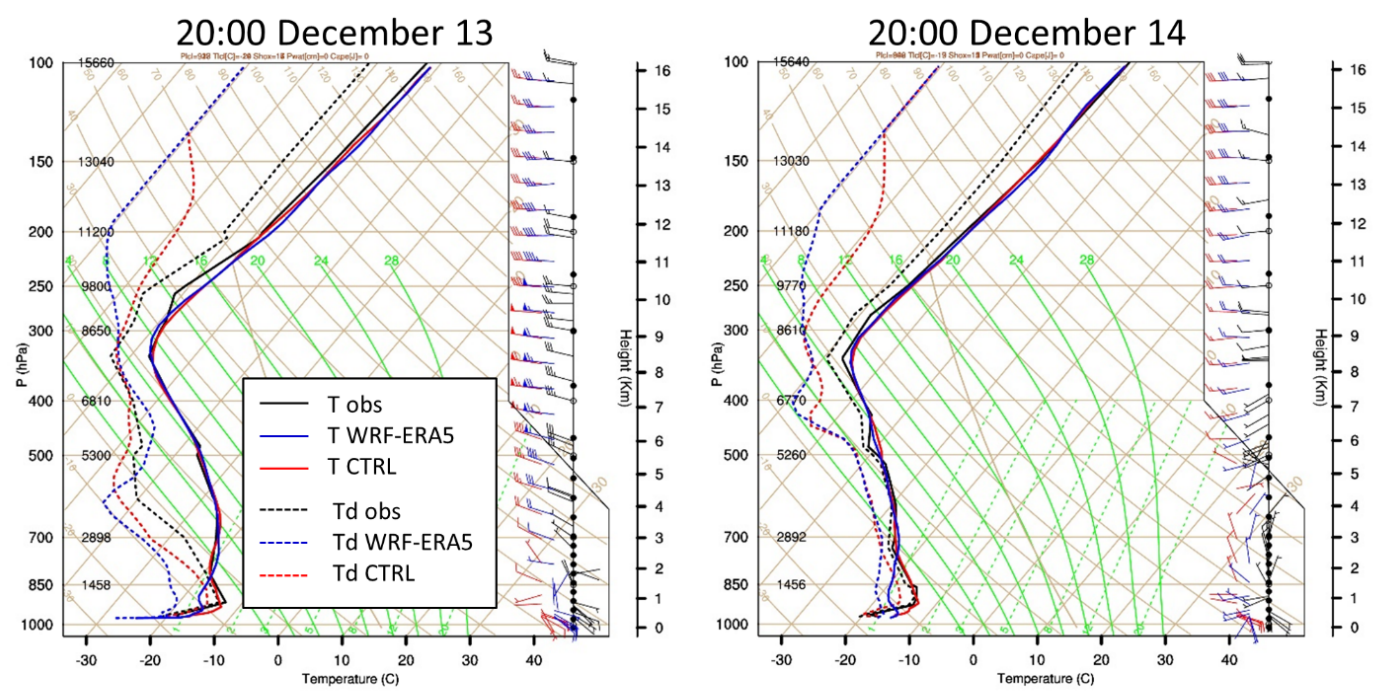

20:00 December 15
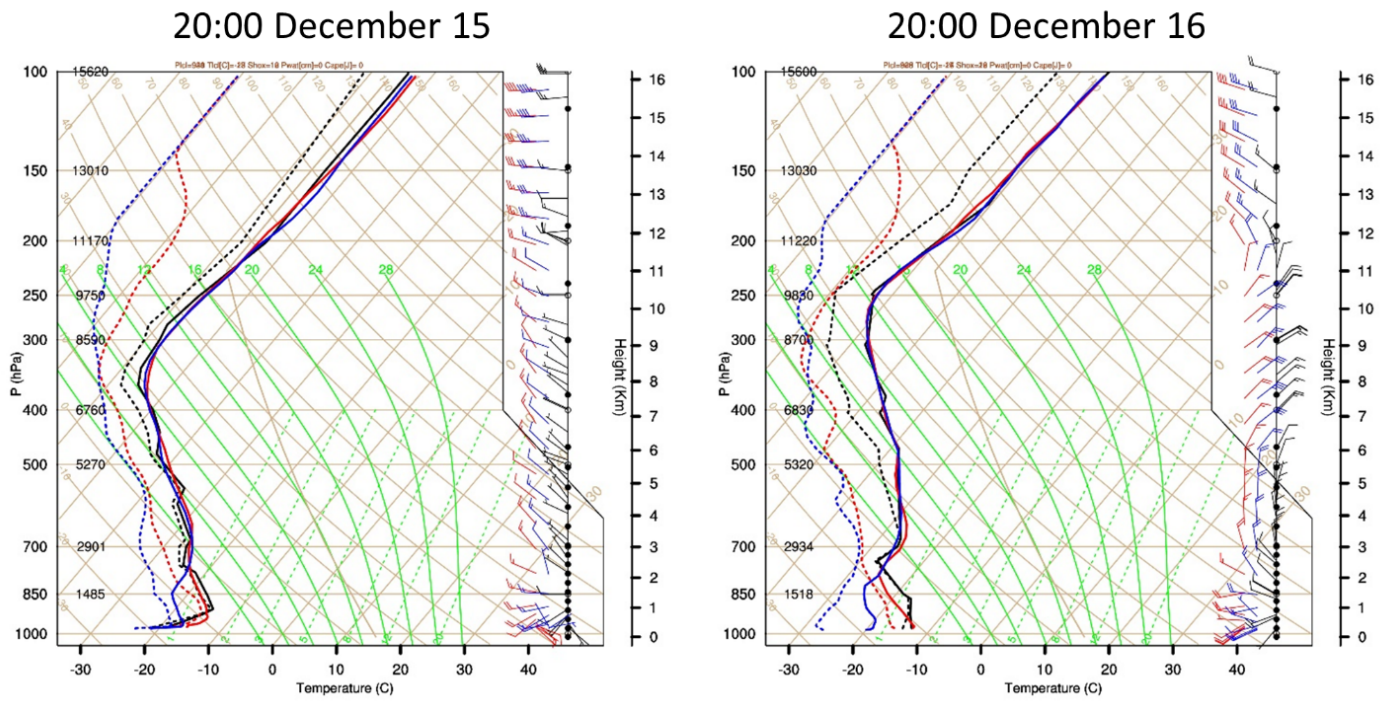

Figure 8. Skew-T diagram at Ust-Barguzin station on 13-16 December 2012, according to observations (black curves and wind barbs) and WRF-ERA5 (blue) and CTRL (red) experiments. Solid curves show air temperature $T$, dashed curves show dew point temperature $T d$.

tures of orography in the north of Baikal formed a north wind blowing along the main axis of the lake over the northern part, in orography-formed corridor, with a western and northwestern background flow (Figure 9). The local name for this wind is "verkhovik", or "angara". High mountains almost completely blocked the cold air coming from the west and northwest. At the same time, to the south, where the height of the mountains decreases, westerly winds of the downslope windstorm type (local names are "gorniy" and "sarma") were noted (Figure 9). On 12 and 15 December, when mesocyclones occurred, velocity of the incoming flow was higher than other days and the pattern of winds on these two days was very similar (Figure 9): moderate winds downwind from gaps in the south of the lake, a moderately strong south wind in the center of the lake and narrow jets of gap winds in combination with a weak northern wind ("verkhovik") in the northernmost part. Such a combination of local winds is typical for this time of the year and in the Baikal Wind Atlas belongs to a special "northwestern" type [Savinova, 1977]. In the area of Svyatoj Nos Peninsula, the vortex arose during the collision of two orographic flows, northern and western (Figure 9). In addition, a wind wake was noted above the surface layer in this region due to air blocking by the mountains of the northern Baikal. Strong 


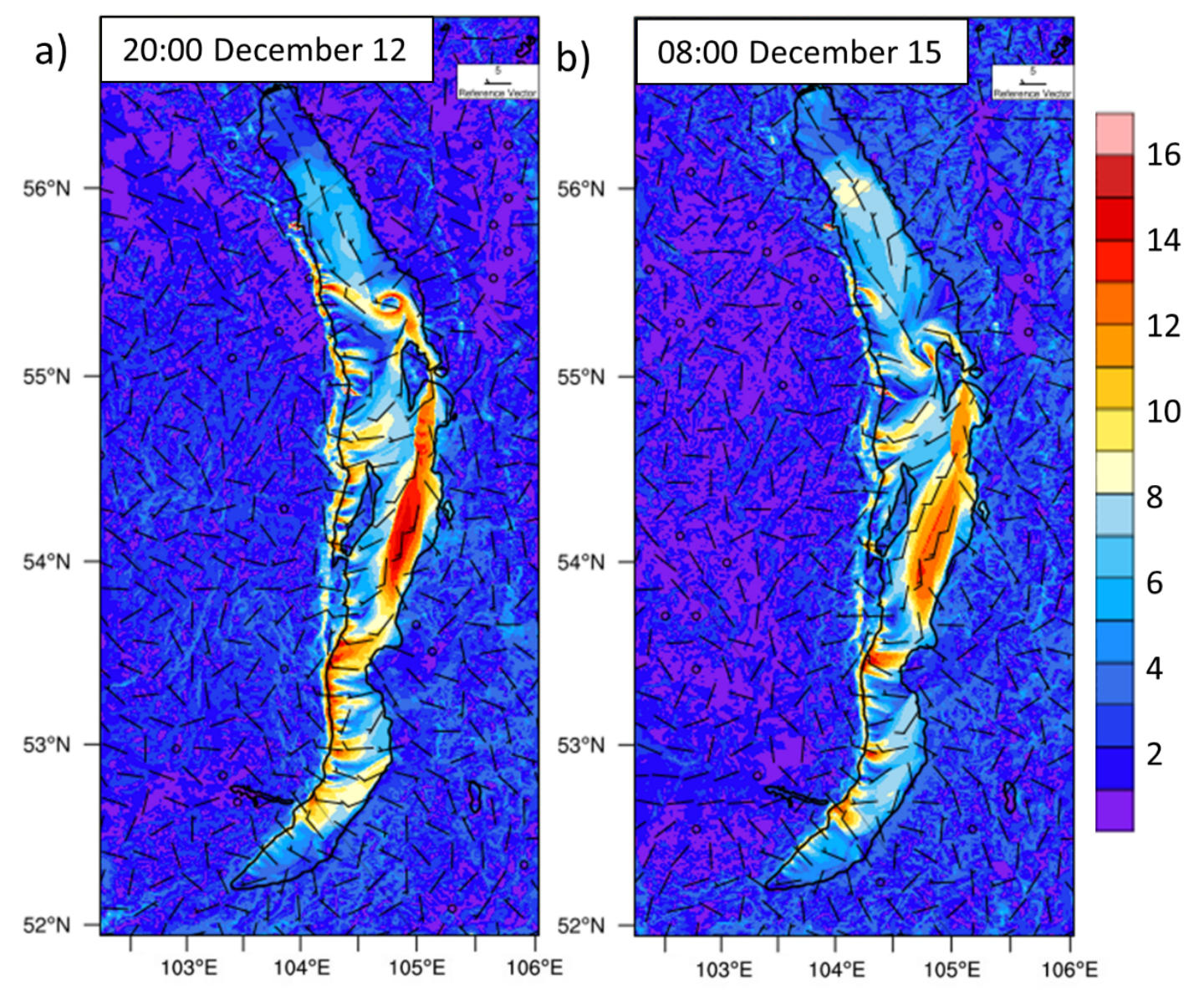

Figure 9. Simulated sea-level pressure over the lake (contours, every $1 \mathrm{hPa}$ ) and 10-m wind speed (barbs and color, in $\mathrm{m} \mathrm{s}^{-1}$ ) at 20:00 12 December (a) and 08:00 16 December (b).

wind is an unfavorable factor (all other things being equal) for the formation of lake vortices, since the background flow disturb the breeze circulation (as is the case in the FLAT experiment). In CTRL experiment, the ratio of the flow velocity (we took $10-\mathrm{m}$ northern wind speed) to the path traveled by the flow over the lake (the distance from the northern point of the lake to the vortex origin area) was small, namely 0.035 . This value fell within the range typical for lake vortices [Laird and Kristovich, 2004.

It is easy to verify that convergence was the main factor in the formation of a given vortex by calculating all the terms of the vortex (1). Figure 10a shows the time course of the components of (1) calculated at $850-\mathrm{hPa}$ level and averaged over a radius of $20 \mathrm{~km}$ from the vortex center (the latter is determined as a grid point with the minimum sea-level pressure). Relative vorticity in the vortex had typ- ical values of $(1-2) \times 10^{-3} \mathrm{~s}^{-1}$. Polar lows usually have the same vorticity order [Yanase et al., 2004]. The contribution of vorticity convergence (red line in Figure 10a) to vorticity generation (the latter was calculated as the sum of all terms on the righthand side of (1) (black line in Figure 10a)), was the largest among other terms, and the baroclinic term was several orders of magnitude smaller than all the rest.

Orography not only modulated wind filed, but also significantly modified the temperature stratification over the lake. The air temperature in the lower troposphere over the lake in the experiment with orography was significantly higher than in the experiment without it due to the blocking of cold air by mountains and adiabatic heating of that part of the air that crosses the ridge. For instance, the temperature difference between the CTRL and FLAT experiments on 15 December at 

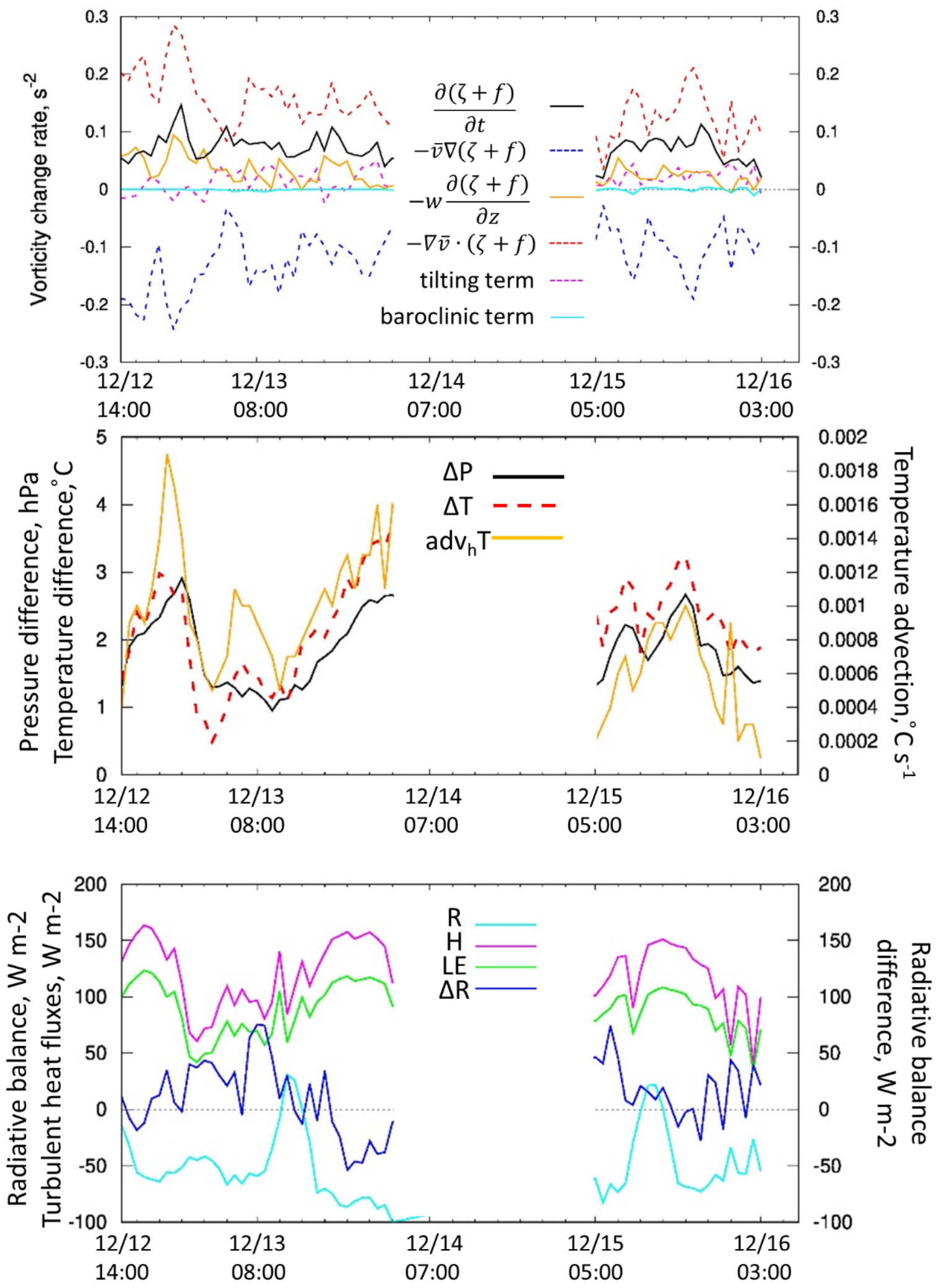

Figure 10. Evolution of vorticity equation terms at 850 -hPa level (a), vortex intensity and temperature changes (b) and heat budget terms (c) inside the vortex (see explanations in the text). 
850-hPa level was about 4 degrees, and near the surface it was 10 degrees (Figure 11). It would seem that in this case orography should, on the contrary, enhance stratification, since the temperature gradient between water and air decreases. Indeed, this is exactly what happens in the lowermost nearsurface layer. More importantly, however, was that the mountains blocked the incoming flow with its strong inversion (Figure 11, grey line). This inversion, orography being removed, did not have time to be destructed completely when air moves over the lake and, as a result, the lower unstable layer was capped by the inversion layer, which did not allow the development of thick convective clouds. An even stronger inversion with a lower boundary near the surface was also formed in the WRF-ERA5 experiment (Figure 11) due to near-surface air cooling from the ice and adiabatic heating above (with a maximum at an altitude of 200-300 m a.g.l.). In the control experiment, the adiabatic heating of air did not lead to an inversion, since the temperature of the adiabatically heated air was still much lower than the surface temperature of a warm lake. Therefore, the layer with weakly unstable stratification extended from the surface to an altitude of $2 \mathrm{~km}$ a.g.l.; the temperature gradient was close to the dry adiabatic lapse rate in the lower layer and to the wet adiabatic lapse rate in the cloud layer.

Considered vortex had a warm core Figure 5, Figure 5d) in its lower part and a cold core and flow divergence in its upper part (at 700-hPa level). The temperature at 850 -hPa level was 1-2 degrees higher in the center of the vortex than the ambient temperature (Figure 5d, Figure 11). The presence of a warm core in a mesocyclone can be caused by the release of condensation heat, but also by other reasons. For instance, Yanase et al. 2004 estimated the thermodynamic equation terms and showed that the downward motions in the eye of the vortex was the main cause of a warm core. However, no connection was found between the vortex eye and the warm core intensity in our experiments. Figure 11 shows the profile of the temperature difference (black curve) between points A (inside the vortex) and B (outside the vortex). The profile had a maximum inside the cloud layer (the level of condensation was located at an altitude of $250 \mathrm{~m}$ a.g.l.) and was obviously caused by the release of the condensation heat. The combination of the condensation heat with cooling at the cloud top led to deepening of the unstable layer to an

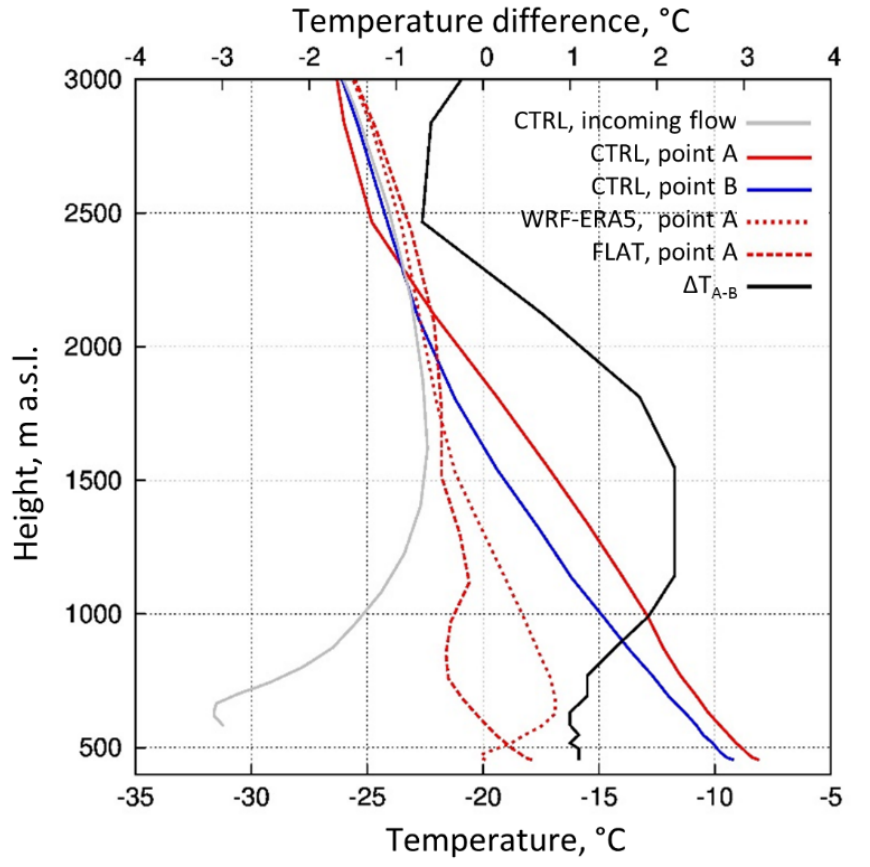

Figure 11. Vertical profile of air temperature at point $\mathrm{A}$ in all experiments and also at point $\mathrm{B}$ and in the incoming flow (see Figure 1) in CTRL experiment and temperature difference $\Delta T_{A-B}$ between points $\mathrm{A}$ and B at 12:00 15 December.

altitude of $2 \mathrm{~km}$ a.g.l., while outside the vortex the unstable layer extended only up to $1 \mathrm{~km}$ a.g.l. Temperature stratification outside the vortex could also be unstable (in areas where there were no gap winds, as at point $\mathrm{B}$ at the time considered in Figure 11, however, this did not lead to the formation of such thick clouds as in mesocyclone. This was due to very small CAPE value, so that an additional driving force was needed for cloud growth. Upward motions caused by flow convergence in the mesocyclone was such a force. That is, if all thermodynamic fields are left the same as in the control experiment, but the orography that generates the initial shear vorticity is removed, then deep convection does not form due to the insufficient amount of the energy of convective instability.

A warm core was also noted near the surface (Figure 5k, Figure 11); the maximum air temperature in the surface layer over the entire lake was noted in the center of the vortex. To clarify the reasons for this temperature anomaly near the surface, we calculated the horizontal temperature advection $a d v_{h} T$ (average within a radius of $20 \mathrm{~km}$ from the vortex center) at the lowest model level (Figure 10p) and the radiative balance anomaly 
$\Delta R$ (the difference in the average radiative balance at the vortex center and outside, at point B) (Figure 10;). Vertical temperature advection was not considered due to small vertical velocity values at the lowest level. Figure 10p also shows the sea-level pressure difference $\Delta P$ (value at point $\mathrm{B}$ minus value at the center) as a measure of the vortex intensity, and the temperature difference $\Delta T$ at $2 \mathrm{~m}$ (value at the center minus value at point B) as a measure of temperature anomaly intensity. During periods of maximum vortex intensity, the air temperature at $2 \mathrm{~m}$ in the vortex center was 3-4 degrees higher than the ambient temperature (Figure 10). Average values (averaged within a radius of $20 \mathrm{~km}$ from the vortex center) of the surface radiative balance $R$ and turbulent fluxes of sensible $H$ and latent LE heat fluxes (positive if directed from the surface to the atmosphere) are shown in Figure 10.

Average turbulent heat fluxes near the vortex center did not exceed $170 \mathrm{~W} \mathrm{~m}^{-2}$ and generally were no more than values outside the vortex. The radiative balance in the vortex at night (which lasts about 15 hours) was noticeably higher than outside it (Figure 10k) due to downward long-wave radiation from clouds. Although correlation between the radiative balance difference and temperature anomaly was not high, radiative factor could affect the temperature with some delay, as an accumulated effect. At the same time, temperature anomaly was highly correlated with the value of temperature advection (Figure 10b). Thus, the main cause of the near-surface vortex warm core could be considered the advection of warm air heated during the turbulent heat exchange with the surface, though the factor of radiative balance also took place. Figure 10b also demonstrates a high correlation between the temperature anomaly and vortex intensity with little or no time lag, which indicates a positive feedback: pressure drop enhances convergence and wind speed, and hence temperature advection; temperature anomaly increases, leading to a further pressure drop.

Thus, we can draw the following scheme of the vortex development on the basis of simulations carried out. The flow convergence under the influence of local orographic features according to the vorticity equation led to the appearance of positive vorticity (i.e., a release of the barotropic instability). Then, vertical motions began due to convergence (according to the continuity equation); these motions were eased by weakly unstable temperature stratification in the lowest 2 -km layer (i.e., a release of the thermal instability). Unstable stratification arose due to the advection of a relatively cold air from the land and, at the same time, due to the partial blocking of the incoming flow with inversion. Orography was the main trigger for the mesocyclone generation, although it was the lake effect, that allowed the vortex and associated convective clouds to develop. Both the lake effect and orography in our case are necessary, but not sufficient conditions for the formation of a full-sized vortex, and a sufficient condition is the simultaneous action of these two factors.

The vortex under study had similar dimensions, the type of cloudiness, and is observed under similar conditions as other lake vortices. At the same time, our vortex was even more similar to a tropical cyclone by the type of cloudiness, with its spiraliform cloud features, than to polar vortices, in which the cloudiness usually takes the form of a comma. The main difference between this vortex and vortices over the Great Lakes is that in the case of Lake Baikal, favorable wind and thermal conditions for vortex generation are created by orography, by analogy with polar lows formed under the influence of the Greenland orography [Kristjánsson et al., 2011] or katabatic flows off the coast of Antarctica [Gallée, 1995]. The vortex intensification mechanisms CISK and WISHE both could take place in our case. The vortex warm core was formed throughout the entire lower troposphere due to the advection of warm air heated in the process of turbulent heat exchange with the surface and long-wave radiation of cloudiness near the surface, and additionally due to the heat of condensation in the cloud layer. Under conditions of suppressed turbulent heat exchange and a source of moisture for the formation of deep convection (in the WRF-ERA5 experiment), only a very weak vortex was formed, which was not traced even at an altitude of $1 \mathrm{~km}$ a.g.l.

\section{Conclusions}

This study, to our knowledge, the first time concerns the analysis and simulation of lake-effect convection and associated mesoscale circulations on Lake Baikal. Genesis and development of a meso- 
cyclone over Lake Baikal in December 2012 were considered mostly based on numerical modeling using the WRF-ARW model.

Mesoscale vortex with a diameter of about 60 $\mathrm{km}$, corresponding to meso- $\beta$ scale, occurred over the northern half of Lake Baikal under the influence of two factors, that are heat and moisture fluxes from the ice-free lake surface (lake effect) and orography. Numerical experiments showed that, in the absence of at least one of these factors, the mesocyclone is not formed. In the experiment with ERA5 reanalysis used as initial and boundary conditions, the northern half of the lake was covered with ice (due to incorrect ice in ERA5 for this case) and convection was suppressed. However, although this experiment was very different from observations, weak near-surface vortices in the northern part of the lake were still formed, which indicates the important role of orography in this process.

Development of this mesocyclone can be described as follows. Orography around the lake creates a flow convergence over the lake due to the convergence of orographic flows characteristic of Lake Baikal, as well as due to the fact that the breeze circulation is not disturbed by the background flow due to the partial flow blocking by mountains. As a result, an area of low pressure and upward motions is formed over the lake. Thus, this vortex originated from the so-called shear vortex (due to horizontal wind shear), and therefore the vortex was barotropic. At the same time, the intensification of upward motions in the vortex is possible due to unstable temperature stratification, which is largely formed under the influence of orography (due to blocking of the incoming flow by mountains), as well as due to local mesoscale advection of air heated by turbulent heat exchange with the lake surface in the lower layer, and also due to an increase in the downward long-wave radiation under the clouds and the release of condensation heat in the clouds.

The values of the convective available potential energy in our case were rather small; therefore, the cloudiness outside the vortex had a small vertical scale and the amount of precipitation was small. Inside the vortex, where, according to simulations, the snowfall intensity reached $20 \mathrm{~mm} / 3 \mathrm{~h}$, the growth of deep convection was caused by forced upward motions due to flow convergence. This means that one should not expect heavy precipi- tation associated with the lake-effect clouds over Lake Baikal under conditions similar to those considered here, unless a mesocyclone or at least a convergence zone has formed.

Although we are studying only one case, this case is typical for this time of year. Indeed, westerly and northwesterly winds prevail over Lake Baikal at the beginning of winter at altitudes above $850-\mathrm{hPa}$ level. Due to the great temperature difference between the unfrozen lake and the cold land, a monsoon (or breeze) circulation used to form, which contributes to the development of local winds. Therefore, the greatest frequency of strong local winds occurs from October to December [Savinova, 1977], before the lake surface is covered with ice. The high frequency of local circulations of the northwestern type according to [Savinova, 1977 creates prerequisites for a high frequency of vortex in the northern half of Lake Baikal (in the area of Svyatoj Nos Peninsula) at this time of the year. Additional studies of lake vortices frequency over Baikal from satellite data and simulations are required to confirm these speculations.

Finally, we would like to emphasize the practical conclusion drawn from the results of this work. The WRF-ARW model can be recommended for regional forecasting of mesoscale circulations over Lake Baikal. Meteorological parameters at the stations and cloud features are reproduced quite accurately in the control experiment. The time and place of mesocyclone appearance in the model generally coincides with the observed ones, although some space shift of the cyclone landfall in the model led to an inaccurate reproduction of the amount of precipitation. The spatial resolution of the model must be high, at least $5 \mathrm{~km}$ [Naydenov, 2015], in order to reproduce all orographic flows, since the vortex is very sensitive to orography. The lake surface temperature in the initial data is also a key parameter, since the inadequacy of the LST leads to a complete failure in the precipitation forecast (Figure 6).

Acknowledgements. Authors are grateful to Alexander V. Gavrikov for help in the model configuring and provided computer resources, and also to Pavel A. Toropov for helpful discussions. The work is funded by Russian Foundation for Basic Research, grant \# 19-55-44028. 


\section{References}

Albright, M., R. Reed, D. Ovens (1995), Origin and structure of a numerically simulated polar low over Hudson Bay, Tellus A, 47, No. 5, 834-848, Crossref

Alcott, T. I., W. J. Steenburgh (2013), Orographic influences on a Great Salt Lake-effect snowstorm, Mon. Weather Rev., 141, No. 7, 2432-2450, Crossref

Charney, J. G., A. Eliassen (1964), On the growth of the hurricane depression, Journal of Atmospheric Sciences, 21, No. 1, 68-75, Crossref

Claud, C., G. Heinemann, et al. (2004), Polar low le Cygne: Satellite observations and numerical simulations, Quarterly Journal of the Royal Meteorological Society, 130, No. 598, 1075-1102, Crossref

Emanuel, K. A., R. Rotunno (1989), Polar lows as Arctic hurricanes, Tellus, 41A, 1-17, Crossref

Gallée, H. (1995), Simulation of the mesocyclonic activity in the Ross Sea, Antarctica, Monthly Weather Review, 123, No. 7, 2051-2069, Crossref

Ghafarian, P., N. Pegahfar, E. Owlad (2017), Multiscale analysis of lake-effect snow over the southwest coast of the Caspian Sea (31 January-5 February 2014), Weather, 73, No. 1, 9-14, Crossref

Forbes, G. S., J. H. Merritt (1984), Mesoscale vortices over the Great Lakes in wintertime, Monthly Weather Review, 112, No. 2, 377-381, Crossref

Heinemann, G. (1997), Idealized simulations of the Antarctic katabatic wind system with a threedimensional mesoscale model, Journal of Geophysical Research: Atmospheres, 102, No. D12, 1382513834, Crossref

Iacono, M. J., J. S. Delamere, E. J. Mlawer, et al. (2008), Radiative forcing by long-lived greenhouse gases: Calculations with the AER radiative transfer models, Journal of Geophysical Research: Atmospheres, 113, No. D13, Crossref

Khoshakhlagh, F., N. Farid Mojtahedi, et al. (2016), Lake effect snow phenomenon and its role on heavy snowfall in the southwest of the Caspian Sea, Geographic Space, 16, No. 53, 41-45.

Klein, T., G. Heinemann (2002), Interaction of katabatic winds and mesocyclones near the eastern coast of Greenland, Meteorological Applications, 9, No. 4, 407-422, Crossref

Kristjánsson, J. E., S. Thorsteinsson, et al. (2011), Orographic influence of east Greenland on a polar low over the Denmark Strait, Quart. J. Roy. Meteor. Soc., 137, 1773-1789, Crossref

Laird, N. F. (1999), Observation of coexisting mesoscale lake-effect vortices over the western Great Lakes, Monthly Weather Review, 127, No. 6, $1137-$ 1141, Crossref

Laird, N. F., D. A. R. Kristovich (2004), Comparison of Observations with Idealized Model Results for a Method to Resolve Winter Lake-Effect Mesoscale Morphology, Monthly Weather Review, 132, No. 5, 1093-1103, Crossref
Laird, N. F., D. A. Kristovich, J. E. Walsh (2003), Idealized model simulations examining the mesoscale structure of winter lake-effect circulations, Monthly Weather Review, 131, No. 1, 206-221, Crossref

Lim, K. S. S., S. Y. Hong (2010), Development of an effective double-moment cloud microphysics scheme with prognostic cloud condensation nuclei (CCN) for weather and climate models, Monthly Weather Review, 138, No. 5, 1587-1612, Crossref

Mizandrontseva, K. N. (1970), Climate and Climatic Resources of Baikal and the Baikal Region, 153 pp. Nauka, Moscow. (in Russian)

Nakanishi, M., H. Niino (2006), An improved Mellor-Yamada level-3 model: Its numerical stability and application to a regional prediction of advection fog, Boundary-Layer Meteorology, 119, No. 2, 397407, Crossref

Naydenov, P. A., J. Lkhamzhavin (2015), Study of storm winds over Lake Baikal using the non-hydrostatic numerical model WRF (Weather Research and Forecasting), Izvestiya Irkutskogo Gosudarstvennogo Universiteta. Seriya: Nauki o Zemle, 11, 55-63. (in Russian)

Nicholls, J. F., R. Toumi (2014), On the lake effects of the Caspian Sea, Q. J. R. Meteorol. Soc., 140, No. 681, 1399-1408, Crossref

Niziol, T. A. (1987), Operational forecasting of lake effect snowfall in western and central New York, Weather Forecast, 2, No. 4, 310-321, Crossref

Pease, S. R., W. A. Lyons, et al. (1988), Mesoscale spiral vortex embedded within a Lake Michigan snow squall band: High resolution satellite observations and numerical model simulations, Monthly Weather Review, 116, No. 6, 1374-1380, Crossref

Rasmussen, E. A., J. Turner (2003), Polar Lows: Mesoscale Weather Systems in the Polar Regions, 628 pp. Cambridge University Press, Cambridge. Crossref

Saha, S., S. Moorthi, et al. (2011), NCEP Climate Forecast System Version 2 (CFSv2) 6-hourly Products, Research Data Archive at the National Center for Atmospheric Research Computational and Information Systems Laboratory, Crossref

Savinova, N. V. (1977), Atlas of Waves and Winds of Lake Baikal, 117 pp. Gidrometeoizdat, Leningrad.

Shestakova, A. A., P. A. Toropov (2021), Orographic and lake effect on extreme precipitation on the Iranian coast of the Caspian Sea: a case study, Meteorology and Atmospheric Physics, 133, No. 1, 69-84, Crossref

Terpstra, A., S. I. Watanabe (2020), Polar Lows, Oxford Research Encyclopedia of Climate Science, Oxford, Oxford. Crossref

Tewari, M., F. Chen, et al. (2004), Implementation and verification of the unified NOAH land surface model in the WRF model (Formerly Paper Number 17.5), 20th conference on weather analysis and forecasting/16th conference on numerical weather prediction p. 11-15, Seattle, Washington, USA. 
(https://ams.confex.com/ams/84Annual/techprograrn Yanase, W., G. Fu, et al. (2004), A Polar /paper_69061.htm) Low over the Japan Sea on 21 January 1997. Part II:

Verezemskaya, P. S., V. M. Stepanenko (2016), Numerical simulation of the structure and evolution of a polar mesocyclone over the Kara Sea. Part 1. Model validation and estimation of instability mechanisms, Russian Meteorology and Hydrology, 41, No. 6, 425434, Crossref

Watanabe, S. I. I., H. Niino, W. Yanase (2018), Composite analysis of polar mesocyclones over the western part of the Sea of Japan, Monthly Weather Review, 146, No. 4, 985-1004, Crossref
A Numerical Study, Monthly Weather Review, 132, No. 7, 1552-1574, Crossref

\section{Corresponding author:}

A. A. Shestakova, A. M. Obukhov Institute of Atmospheric Physics Russian Academy of Science, Moscow, Russia. (shestakova.aa.92@gmail.com) 